\title{
The mediating sex-specific effect of psychological distress on the relationship between adverse childhood experiences and current smoking among adults
}

Tara W Strine ${ }^{1,7^{*}}$, Valerie J Edwards ${ }^{2}$, Shanta R Dube ${ }^{3}$, Morton Wagenfeld $^{4,5}$, Satvinder Dhingra' ${ }^{1}$ Angela Witt Prehn ${ }^{4}$, Sandra Rasmussen ${ }^{4,6}$, Lela McKnight-Eily ${ }^{2}$ and Janet B Croft ${ }^{2}$

\begin{abstract}
Background: Research suggests that ACEs have a long-term impact on the behavioral, emotional, and cognitive development of children. These disruptions can lead to adoption of unhealthy coping behaviors throughout the lifespan. The present study sought to examine psychological distress as a potential mediator of sex-specific associations between adverse childhood experiences (ACEs) and adult smoking.
\end{abstract}

Method: Data from 7,210 Kaiser-Permanente members in San Diego California collected between April and October 1997 were used.

Results: Among women, psychological distress mediated a significant portion of the association between ACEs and smoking (21\% for emotional abuse, 16\% for physical abuse, 15\% for physical neglect, $10 \%$ for parental separation or divorce). Among men, the associations between ACEs and smoking were not significant.

Conclusions: These findings suggest that for women, current smoking cessation strategies may benefit from understanding the potential role of childhood trauma.

Keywords: Smoking, Adverse childhood experiences, Pyschological distress, Mediation analysis

\section{Background}

Adverse childhood experiences (ACEs), which can include abuse (emotional, physical, and sexual), neglect (emotional and physical), and household dysfunction, are common among children [1]. In 2010 alone, maltreatment was reported for 695,000 US children (9.2 per 1000 children) [2]. In the largest study of ACEs, over $60 \%$ of 17,337 adults reported a history of at least one ACE [3].

Research suggests that ACEs have a long-term impact on the behavioral, emotional, and cognitive development of children [4-6]. This deleterious impact may be due to

\footnotetext{
*Correspondence: tws2@cdc.gov

${ }^{1}$ Office of Public Health Preparedness and Response, Office of Science and Public Health Practice, Centers for Disease Control and Prevention, Atlanta, GA, USA

${ }^{7}$ Office of Surveillance, Epidemiology, and Laboratory Services, Centers for Disease Control and Prevention, 2500 Century Pkwy Mailstop E-97, Atlanta, GA 30345, USA

Full list of author information is available at the end of the article
}

an unhealthy environment that impedes the resolution of early life development issues [7] as well as actual modifications in brain anatomy and functioning during important developmental periods [8]. These disruptions can lead to adoption of unhealthy coping behaviors throughout the lifespan $[9,10]$ as well as maladaptive psychological functioning or psychological distress [11-14].

Persons who have experienced ACEs and psychological distress may smoke as a method to compensate for deficiencies in social and emotional development as well as a way to self-medicate biological dysregulations produced by abuse or neglect [5,15-18]. Smoking may be viewed as a viable coping option because of its perceived anxiolytic and sedative properties - for example, it's ability to modify mood, manage dysphoria, regulate negative affect, control situational anxiety, and improve concentration [19-23]. As evidence, studies have shown that nicotine reduces anger in both smokers and nonsmokers 
with high hostility [24,25] and depressive symptoms in both nonsmokers and smokers with depression [26-28].

Psychiatric disorders are one of the most cited risk factors for nicotine dependence [29]. Longitudinal studies have suggested that depression [30-35], behavioral disorders [36], and anxiety [34], particularly PTSD [37], may increase the risk of subsequent smoking. Research has also implicated psychiatric conditions such as schizophrenia [38-41] and ADHD [42-44] as risk factors for smoking.

Several studies have examined the potential mediating effect of mental disorders on the relationship between ACEs and drug use. Studies conducted by Douglas et al. [45] and Lo and Chen [46] suggest that the relationship between childhood abuse and substance dependence may be partially mediated by mood and anxiety disorders. DeWit et al. [47], implicate social phobia as the mediator between adverse life events and chronic stress in childhood and drug dependence in adulthood. According to a literature review conducted by Simpson and Miller [48], psychiatric conditions such as depression and anxiety disorders mediate the relationship between child abuse and substance use disorders in women. Moreover, in a study conducted by White and Widom [49], the authors concluded that PTSD among maltreated girls may increase the risk of subsequent substance use problems.

Despite the fact that smoking continues to be the leading cause of death and disability in the United States [50], the magnitude and complexity of the relationship between ACEs and smoking is only beginning to be understood. Research conducted thus far suggests that ACEs are significantly associated with early smoking initiation, smoking maintenance, heavy smoking, and lifetime smoking across birth cohorts [51-56].

Because of the pervasive effect of ACEs throughout the life course and the deleterious effect of smoking on health, we sought to examine the potential mediating effect of psychological distress on the relationship between ACEs and current adult smoking. Moreover, as current research suggests that child abuse and neglect may affect men and women differently [57] and that stressors leading to smoking initiation and maintenance may vary by sex [58-62], the relationships between ACEs and smoking were further explored by sex. The purpose of this study was threefold: 1. to examine the relationships between ACEs, psychological distress, and adult smoking; 2 . to determine if there were sex differences in the relationships between ACEs, psychological distress, and adult smoking, and 3. to determine if psychological distress mediated the relationship between ACEs and adult smoking among males and females.

\section{Methods}

\section{Study setting and participants}

The ACE Study is one of the largest studies to examine childhood trauma as a precursor of adult health in a managed care sample [63]. Data for the current study are based upon Wave II of the ACE Study, which were collected between April and October of 1997. These data were used to examine the relationship between multiple categories of childhood trauma (ACEs) and health and behavioral outcomes later in life. Participants were drawn from adult members of the Kaiser Permanente Medical Care Program in San Diego, California, undergoing a free comprehensive medical examination through the Health Appraisal Clinic (HAC), Department of Preventive Medicine [64].

A total of 13,330 Kaiser Health Plan members completed standardized medical evaluations at the HAC from April through October of 1997. Questionnaires were completed by 8,667 San Diego, California, Kaiser Permanente Health Maintenance Organization members who agreed to participate in the survey. Among these, 7,210 (83.2\%) respondents completed information for the study variables and were included in the analyses (3,895 females and 3,315 males).

\section{Survey methods and variable definitions}

Prior to the medical examination at the clinic, each Kaiser member attending the San Diego HAC completed a standardized health appraisal questionnaire and the Standard Form-36 (SF-36) questionnaire, which was used to assess functional health and well-being $[65,66]$. After the physical exam, patients were mailed the study's Family Health History (FHH), a 168-item questionnaire that covers a broad range of childhood exposures and current health behaviors. Participation was voluntary, and patients were assured that the $\mathrm{FHH}$ would not become part of their medical record.

Adverse childhood experiences were defined using items from the FHH. The following ten ACE categories were assessed: emotional abuse (2 questions), physical abuse (2 questions), sexual abuse (4 questions), emotional neglect (5 questions), physical neglect (5 questions), witnessing domestic violence against mother or stepmother (4 questions), alcoholic or drug-abusing family members (2 questions), mentally ill household members (2 questions), parents separated or divorced, and incarcerated household members (1 question each) (Table 1). Verbatim ACE study questions can be found at: http://www.cdc.gov/ace/questionnaires.htm. Questions from published surveys were used to construct these ACE items. Questions adapted from the Conflicts Tactics Scale were used to define psychological and physical abuse during childhood and to define violence against the respondent's mother or stepmother [67]. Four questions adapted from the Wyatt Sexual History Questionnaire [68] were used to define sexual abuse during childhood. Questions about exposure to alcohol or drug abuse during childhood were taken from the 1988 
Table 1 Definitions of abuse, neglect, and household dysfunction that occurred before age 19 years

\begin{tabular}{|c|c|}
\hline Category & Definitions \\
\hline \multicolumn{2}{|l|}{ Abuse } \\
\hline \multirow[t]{3}{*}{ Emotional } & At least one of the following responses: \\
\hline & 1. Often or very often a parent or other adult in the household swore at you, insulted you, or put you down. \\
\hline & 2. Sometimes, often, or very often they acted in a way that made you think that you might be physically hurt. \\
\hline \multirow[t]{3}{*}{ Physical } & At least one of the following responses: \\
\hline & 1. Sometimes, often, or very often you were pushed, grabbed, slapped, or had something thrown at you. \\
\hline & 2. Sometimes, often, or very often hit so hard that you had marks or were injured. \\
\hline \multirow[t]{5}{*}{ Sexual } & At least one affirmative (yes) response about an adult or a person at least 5 years older: \\
\hline & 1. Ever touched or fondled you in a sexual way. \\
\hline & 2. Had you touch their body in a sexual way. \\
\hline & 3. Attempted oral, anal, or vaginal intercourse with you. \\
\hline & 4. Actually had oral, anal, or vaginal intercourse with you. \\
\hline \multicolumn{2}{|l|}{ Neglect } \\
\hline \multirow[t]{7}{*}{ Emotional } & $\begin{array}{l}5 \text { Childhood Trauma Questionnaire (CTQ) questions (Bernstein, et al., 1994) had possible responses of "never true', "rarely true", } \\
\text { "sometimes true", "often true", or "very often true". Responses were reverse scored on a Likert scale ranging from } 5 \text { to 1, respectively. }\end{array}$ \\
\hline & 1. There is someone in my family who helped me feel important or special. \\
\hline & 2. I felt loved. \\
\hline & 3. People in my family looked out for each other. \\
\hline & 4. People in my family felt close to each other. \\
\hline & 5. My family was a source of strength and support. \\
\hline & $\begin{array}{l}\text { A total cumulative score of } 15 \text { and higher (moderate to extreme on the CTQ clinical scale) defined childhood emotional neglect } \\
\text { (Bernstein, et al., 1994). }\end{array}$ \\
\hline \multirow[t]{7}{*}{ Physical } & $\begin{array}{l}5 \text { Childhood Trauma Questionnaire (CTQ) questions (Bernstein, et al., 1994) had possible responses of "never true', "rarely true", } \\
\text { "sometimes true", "often true", or "very often true". Responses were scored on a Likert scale ranging from } 1 \text { to } 5 \text {, respectively with } \\
\text { items } 2 \text { and } 5 \text { reverse scored ( } 5 \text { to 1, respectively).: }\end{array}$ \\
\hline & 1. You did not get enough to eat. \\
\hline & 2. You knew there was someone to take care of you and protect you. \\
\hline & 3. Your parents were too drunk or high to take care of the family. \\
\hline & 4. You had to wear dirty clothes. \\
\hline & 5. There was someone to take you to the doctor if you needed it. \\
\hline & $\begin{array}{l}\text { A total cumulative score of } 10 \text { or higher (moderate to extreme on the CTQ clinical scale) defined childhood physical neglect } \\
\text { (Bernstein, et al., 1994). }\end{array}$ \\
\hline \multicolumn{2}{|l|}{ Household dysfunction } \\
\hline \multirow[t]{5}{*}{ Witnessing domestic violence } & At least one affirmative (yes) response to the following about your mother or stepmother: \\
\hline & 1. Sometimes, often, or very often was pushed, grabbed, slapped, or had something thrown at her. \\
\hline & 2. Sometimes, often, or very often was kicked, bitten, hit with a fist, or hit with something hard. \\
\hline & 3. Was ever repeatedly hit over at least a few minutes. \\
\hline & 4. Was ever threatened or hurt by a knife or gun. \\
\hline \multirow[t]{3}{*}{ Household substance abuse } & At least one affirmative (yes) response about living with anyone (before age 18) who: \\
\hline & 1. Was a problem drinker or alcoholic. \\
\hline & 2. Used street drugs. \\
\hline \multirow[t]{3}{*}{ Household mental illness } & At least one affirmative (yes) response about a household member who: \\
\hline & 1. Was depressed or mentally ill. \\
\hline & 2. Attempted suicide. \\
\hline Parental separation or divorce & Parents were ever separated or divorced. \\
\hline Incarcerated household member & A household member went to prison. \\
\hline
\end{tabular}


National Health Interview Survey [69]. Physical and emotional neglect were assessed by using the Childhood Trauma Questionnaire short form [70].

In addition to examining individual ACEs, an ACE score was constructed to examine the cumulative exposure to the different types of abuse, neglect, and household dysfunction $[3,52,64,71]$. Exposure to any ACE counted as one point, and categories were summed for a total score between 0 and 10 points. The ACE score summarizes the total number of ACEs an adult recalls experiencing as a child or adolescent across the ten categories.

Psychological distress was assessed as a continuous variable and used the Mental Component Summary (MCS) score calculated from the SF-36. The SF-36 is a generic, multipurpose, short-form health survey with 36 questions and eight subscales [66,72]. The eight scales (Physical Functioning, Role Physical, Bodily Pain, General Health, Vitality, Social Functioning, Role Emotional, and Mental Health) form two distinct higher-ordered clusters, designated physical health (PCS) and mental health (MCS), which account for $80 \%-85 \%$ of the variance in the eight scales $[73,74]$. The reliability estimates of the two summary scales have generally exceeded 0.90 [65]. Predictive studies of validity have linked SF-36 scale scores and the MCS score to the clinical course of depression [75-78]. The MCS score is calculated from a complex set of computer-generated algorithms. All eight scales comprise the MCS score, but three scales (Mental Health, Role Emotion, and Social Functioning) correlate most highly and contribute most to the scoring [65]. Role Physical, Bodily Pain, Vitality, Social Functioning, Role Emotional, and Mental Health all reference the past four weeks. Physical Functioning and General Health reference the respondent's current health and functional status [65]. As the mean MCS score decreases, level of psychological distress increases. The general US population mean MCS norm score for males is 50.73 and for females is 49.33 [65].

Current smoking status was assessed using two questions: a) "Have you smoked at least 100 cigarettes in your entire life?, and b) "Do you smoke cigarettes now?" Persons who had smoked at least 100 cigarettes in their lifetime and smoked at the time of the survey were considered adult current smokers [52,79-81].

\section{Statistical analysis}

Mediation analyses were conducted to identify and explain the relationship between ACEs and adult current smoking based on the inclusion of the MCS score as an indicator for psychological distress [82]. In logistic models that included psychological distress and ACEs (individual or total score) as independent variables and adult current smoking as the dependent variable, psychological distress was treated as a potential mediating variable $[82,83]$.
Several criteria must be satisfied in order for mediation analysis to be valid (Figure 1). First, the independent variable (ACEs) must be significantly associated with the dependent variable (adult current smoking) (c coefficient); the mediating variable (psychological distress) must be significantly associated with the dependent variable (adult current smoking) with the independent variable (ACEs) included in the model (b coefficient); and the independent variable (ACEs) must be significantly associated with the mediating variable (psychological distress) (a coefficient) [84]. Second, the independent variable (ACEs) must be known to cause the mediation variable (psychological distress), which in turn causes the dependent variable (adult current smoking) [84].

The Sobel test was used to determine the significance of the indirect effect of the independent variable (ACEs) on the dependent variable (adult current smoking) through the mediator (psychological distress) [85]. Because the dependent variable (adult current smoking) and the independent variable (ACEs) were dichotomous and the mediating variable (psychological distress) was continuous, the coefficients in the mediation analyses were on two different scales. To make the coefficients compatible, we used techniques developed by MacKinon and Dwyer [86] to calculate the Sobel statistic.

All models were first examined without being adjusted and were then adjusted for age group (18-34, 35-54, $55-74$, and 75 years or older), race/ethnicity (white, black, Hispanic, Asian, Native American, and other), education (no high school diploma, high school or general educational development, some college/technical school, and college graduate), parental smoking during childhood (yes vs. no) to control for familial/genetic tendencies to smoke, and alcohol use in the previous month (yes vs. no) given that alcohol and smoking are highly correlated [87]. All statistical analyses were conducted

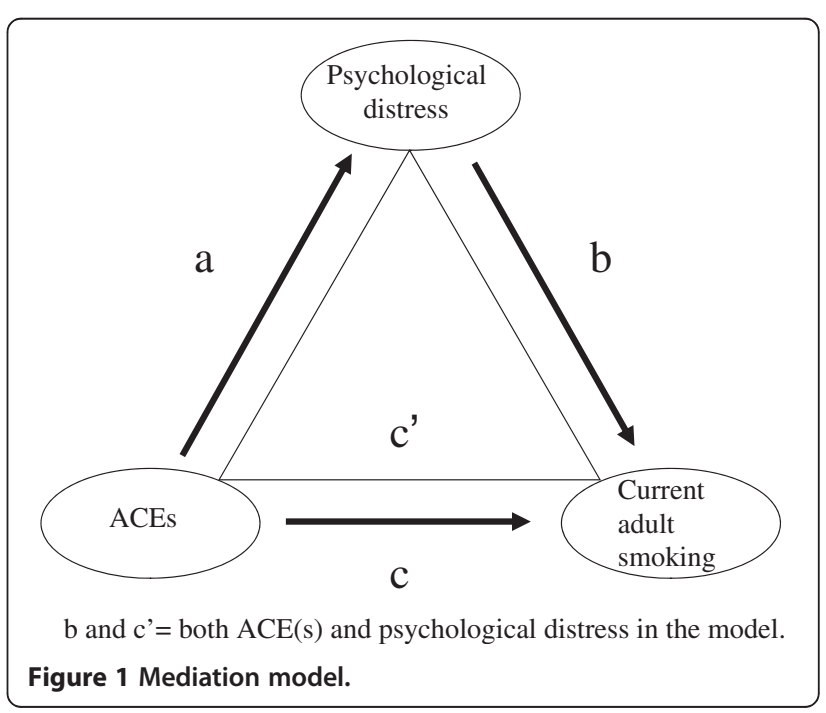


using SAS 9.2 and Excel. Significance was tested at an alpha level of $p<.05$.

\section{Results}

\section{Descriptive characteristics}

The sample consisted of 3,895 females (54.0\%) and 3,315 males (46.0\%). The mean age was 55.9 years; nearly three-quarters of the participants were white and had at least some college or technical education (Table 2). Because there were different sex by effect interactions in the three primary mediation models, all analyses were stratified by sex.

Approximately $56 \%$ of women consumed alcohol in the previous month prior to the survey as did $65 \%$ of men. Over $70 \%$ of men and women reported that one or more parent smoked during their childhood. Approximately $7.6 \%$ of the women in the survey currently smoked as did $8.5 \%$ of men. The MCS score was slightly lower for women than men (51.2 versus 53.2).

Women were significantly more likely than men to report childhood emotional abuse (11.7\% versus $8.2 \%)$, sexual abuse (24.2\% versus $16.7 \%)$, emotional neglect (16.4\% versus $12.2 \%)$, parental separation or divorce
(25.3\% versus $22.4 \%$ ), mental illness in the household (25.0\% versus $14.6 \%$ ), household substance abuse $(29.9 \%$ versus $25.5 \%$ ), and an incarcerated household member (6.9\% versus $4.8 \%)$ (Table 3$)$. Men were significantly more likely than women to report physical abuse $(28.6 \%$ versus $24.6 \%$ ) and neglect (10.5\% versus $8.6 \%$ ).

\section{Relationship between ACEs and current adult smoking}

The unadjusted associations between current adult smoking and ACEs by sex can be found in Figure 2 . After adjustment for sociodemographic characteristics, parental smoking during childhood, and alcohol use in the past month, the odds of adult smoking was at least 1.4 times greater among women who have been emotionally or physically abused, physically neglected, or had experienced parental separation or divorce (versus women who had not experienced each of these ACEs) (Table 4). Notably, the odds of smoking was markedly greater among women WHO had an incarcerated household member during childhood (AOR 2.3, 95\% CI: 1.63.2) (versus women who had not had an incarcerated household member during childhood). While the odds of current adult smoking among women increased as

Table 2 Selected characteristics of the population by sex

\begin{tabular}{|c|c|c|c|c|c|c|}
\hline \multirow{2}{*}{$\begin{array}{l}\text { Characteristics } \\
\text { Age group (years) }\end{array}$} & \multicolumn{2}{|c|}{$\begin{array}{l}\text { Females }(n=3,895) \\
n \%\end{array}$} & \multicolumn{2}{|c|}{$\begin{array}{l}\text { Males }(n=3,315) \\
n \%\end{array}$} & \multicolumn{2}{|c|}{$\begin{array}{l}\text { Chi-square test } \\
\text { Value } p \text {-value (df) }\end{array}$} \\
\hline & & & & & & \\
\hline $18-34$ & 440 & 11.3 & 234 & 7.1 & $52.7(3)$ & $<0.0001$ \\
\hline $35-54$ & 1516 & 38.9 & 1213 & 36.6 & & \\
\hline $55-74$ & 1563 & 40.1 & 1481 & 44.7 & & \\
\hline $75+$ & 376 & 9.7 & 387 & 11.7 & & \\
\hline Mean age (SD) & & $54.8(15.4)$ & & $57.3(14.4)$ & & \\
\hline \multicolumn{7}{|l|}{ Race } \\
\hline White & 2874 & 73.8 & 2517 & 75.9 & $19.3(5)$ & 0.0017 \\
\hline Black & 158 & 4.1 & 132 & 4.0 & & \\
\hline Hispanic & 428 & 11.0 & 340 & 10.3 & & \\
\hline Asian & 353 & 9.1 & 226 & 6.8 & & \\
\hline Native American & 13 & 0.3 & 14 & 0.4 & & \\
\hline Other & 69 & 1.8 & 86 & 2.6 & & \\
\hline \multicolumn{7}{|l|}{ Education } \\
\hline No high school diploma & 306 & 7.9 & 214 & 6.5 & $88.7(3)$ & $<0.0001$ \\
\hline High school/GED & 653 & 16.8 & 402 & 12.1 & & \\
\hline Some college/technical & 1666 & 42.8 & 1280 & 38.6 & & \\
\hline College graduate & 1270 & 32.6 & 1419 & 42.8 & & \\
\hline Alcohol consumed in past month & 2172 & 55.8 & 2158 & 65.1 & $65.0(1)$ & $<0.0001$ \\
\hline History of parental smoking & 2791 & 71.7 & 2434 & 73.4 & $2.8(1)$ & 0.0940 \\
\hline Mean MCS score (SD)* & & $51.2(9.5)$ & & $53.2(8.2)$ & & \\
\hline Current smoker & 294 & 7.6 & 281 & 8.5 & $2.1(1)$ & 0.1470 \\
\hline
\end{tabular}

*Mental Component Summary Score (MCS) based on SF-36. 
Table 3 ACE characteristics of study sample by sex

\begin{tabular}{|c|c|c|c|c|}
\hline \multirow[t]{2}{*}{ ACE } & \multirow{2}{*}{$\begin{array}{l}\text { Females } \\
(n=3,895) \\
\%\end{array}$} & \multirow{2}{*}{$\begin{array}{l}\text { Males } \\
(n=3,315) \\
\%\end{array}$} & \multicolumn{2}{|c|}{ Chi-square test } \\
\hline & & & Value (df) & p-value \\
\hline \multicolumn{5}{|l|}{ Abuse } \\
\hline Emotional & 11.7 & 8.2 & $23.8(1)$ & $<0.0001$ \\
\hline Physical & 24.6 & 28.6 & $14.5(1)$ & 0.0001 \\
\hline Sexual & 24.2 & 16.7 & $61.2(1)$ & $<0.0001$ \\
\hline \multicolumn{5}{|l|}{ Neglect } \\
\hline Emotional & 16.4 & 12.2 & $25.2(1)$ & $<0.0001$ \\
\hline Physical & 8.6 & 10.5 & $7.7(1)$ & 0.0054 \\
\hline \multicolumn{5}{|l|}{ Household dysfunction } \\
\hline $\begin{array}{l}\text { Witnessing domestic } \\
\text { violence }\end{array}$ & 13.6 & 12.1 & $3.8(1)$ & 0.0526 \\
\hline $\begin{array}{l}\text { Parental separation or } \\
\text { divorce }\end{array}$ & 25.3 & 22.4 & $8.6(1)$ & 0.0034 \\
\hline $\begin{array}{l}\text { Mental illness } \\
\text { in household }\end{array}$ & 25.0 & 14.6 & $119.4(1)$ & $<0.0001$ \\
\hline $\begin{array}{l}\text { Household substance } \\
\text { abuse }\end{array}$ & 29.9 & 25.5 & $17.4(1)$ & $<0.0001$ \\
\hline $\begin{array}{l}\text { Incarcerated household } \\
\text { member }\end{array}$ & 6.9 & 4.8 & $14.6(1)$ & 0.0001 \\
\hline \multicolumn{5}{|l|}{ Total number of ACEs } \\
\hline 0 & 32.1 & 34.7 & $50.2(4)$ & $<0.0001$ \\
\hline 1 & 24.1 & 26.9 & & \\
\hline 2 & 14.7 & 16.1 & & \\
\hline 3 & 10.4 & 9.3 & & \\
\hline $4+$ & 18.7 & 13.0 & & \\
\hline
\end{tabular}

the ACE score rose, this association was not significant after adjustment (Figure 1, c coefficient).

Among men, the prevalence and unadjusted odds of current adult smoking was significant for physical abuse, emotional neglect, parental separation or divorce, living with a family member who abused substances, and having an incarcerated household member. Notably, after adjusting for covariates, none of these associations were significant.

\section{Relationship between ACEs and psychological distress}

In the unadjusted models, the mean MCS score, an indicator of psychological distress, was lower among those with any ACE compared to those without the given ACE among both women and men (with the exception of incarcerated household member among men), suggesting increased psychological distress (Figure 3). In the adjusted linear regression models among women (Table 5), all associations between the individual ACEs and the psychological distress indicator were significant except for that in which the independent variable was a childhood exposure to incarcerated household members. Among men, all adjusted associations with the psychological distress indicator were significant except for those in which the independent variable was parental separation or divorce or incarcerated household member. As the ACE score increased in both adjusted and unadjusted linear regression models, the level of psychological distress also increased (i.e., mean score decreased as number of ACEs increased) (Figure 1, a coefficient).
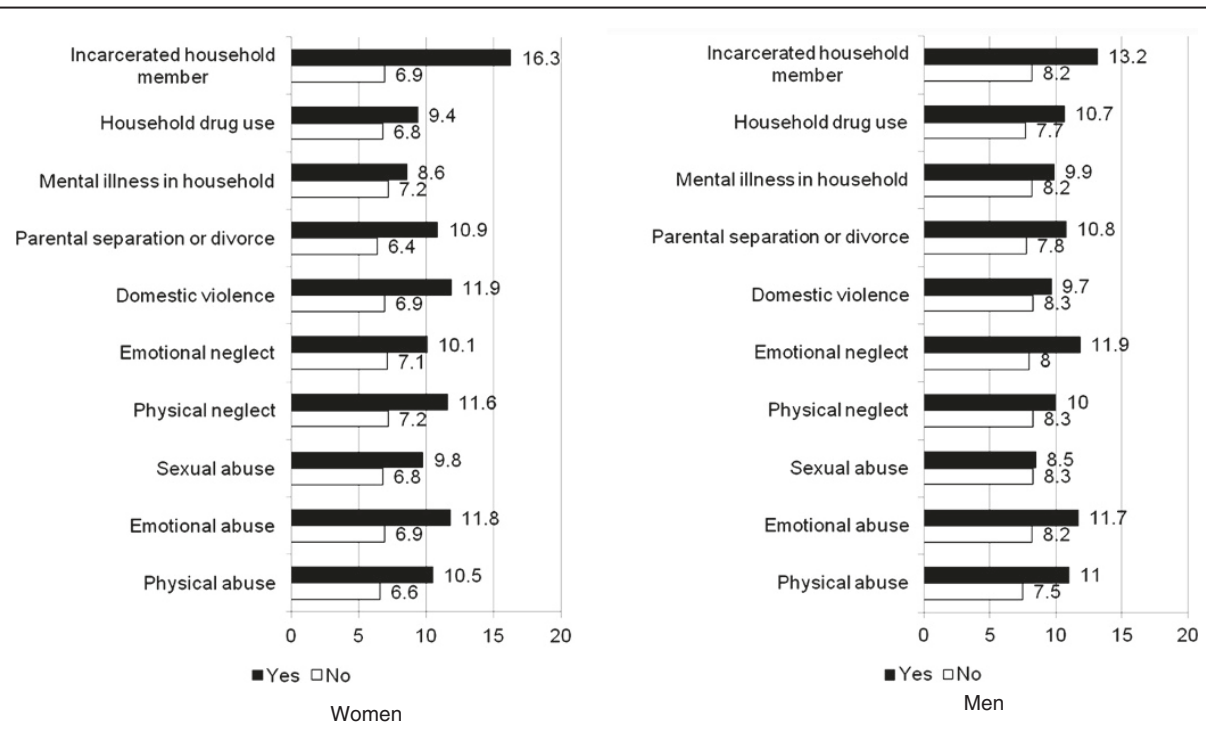

Figure 2 Prevalence of current smoking by ACE status and gender. 
Table 4 Adjusted odds ratios (OR) and $95 \%$ confidence intervals for the relationships between ACEs and adult current smoking, by sex

\begin{tabular}{lll}
\hline ACE & Females adjusted $^{\mathrm{a}}$ & Males adjusted $^{\mathrm{a}}$ \\
& OR $(95 \% \mathrm{Cl})$ & OR $(95 \% \mathrm{Cl})$ \\
\hline
\end{tabular}

\section{Abuse}

Emotional

Yes

No

Physical

Yes

No

Sexual

Yes

No

\section{Neglect}

Emotional

Yes

No

Physical

Yes

No

Household dysfunction

Witnessing domestic violence

Yes

No

Parental separation or divorce

Yes

No

Mental illness in the household

Yes

No

Household substance abuse

Yes

No

Incarcerated household member

Yes

No

$2.3(1.6-3.2)^{*}$

Referent

\section{Referent}

$0.7(0.5-1.0)$

$1.3(0.9-1.8)$

$1.3(0.9-2.0)$

$1.4(1.0-2.0)$

\footnotetext{
a Odds ratios (OR) and $95 \%$ confidence intervals (Cl). Multivariable logistic regression models included age group, race, education, parental smoking during childhood, and alcohol use in past month.
} ${ }^{*} p<0.05$.

\section{Relationship between psychological distress and current adult smoking}

In the models adjusted for sociodemographic characteristics, parental smoking during childhood, and past 30 day consumption of alcohol, the association between psychological distress and current adult smoking was significant for both women (AOR $=0.98$; 95\% CI: 0.97-0.99; Wald chi-square $=15.22, \mathrm{DF}=1, \mathrm{p}$-value $<0.0001)$ and men $(\mathrm{AOR}=0.98 ; 95 \% \mathrm{CI}: 0.97-1.00$; Wald chi-square $=5.73$, $\mathrm{DF}=1, \mathrm{p}=0.0166$ ). With the addition of each ACE in the model, the associations remained significant for women $(\mathrm{AOR}=0.98$; 95\% CI: 0.97-0.99; $\mathrm{p}$-value range: $\mathrm{p}=0.0004$ for model with mental illness in household to $p=0.0014$ for model with emotional abuse) but not men (AOR = $0.99,95 \%$ CI: $0.87-1.00, p$-value range: $p=0.0523$ for the model with sexual abuse to $\mathrm{p}=0.0934$ for the model with incarcerated household member) (Figure 1, b coefficient).

\section{Mediating role of psychological distress on the relationship between ACEs and current adult smoking} Given that after adjusting for covariates, there was no significant association between any of the ACEs and smoking or psychological distress and smoking (with ACEs included) among men, mediation analyses were limited to women. After adjusting for covariates, psychological distress mediated $22 \%$ of the relationship between emotional abuse and current adult smoking, approximately $17 \%$ of the relationship between physical abuse and current adult smoking, $14 \%$ of the relationship between physical neglect and current adult smoking, and about $10 \%$ of the relationship between parental separation or divorce and current adult smoking among women (Table 6) (Figure 1, c' coefficient).

\section{Discussion}

This research reveals several important findings. First, there are differences in the relationship between ACEs, psychological distress, and adult smoking by sex. While the relationships between ACEs and psychological distress was evident among both men and women, after adjusting for covariates, there were not significant relationships between ACEs and smoking or psychological distress and smoking (after each ACE was added to the model) among men. Second, this research suggests that women, particularly those who have experienced emotional or physical abuse, physical neglect, or parental separation or divorce as children may be at particular risk for smoking in adulthood. In fact, approximately $22 \%$ of the relationship between emotional abuse and adult smoking was mediated though psychological distress as was $17 \%$ of the relationship between physical abuse and adults smoking, 14\% of the relationship between physical neglect and adult smoking, and $10 \%$ of the relationship between parental separation and divorce and adult smoking. 

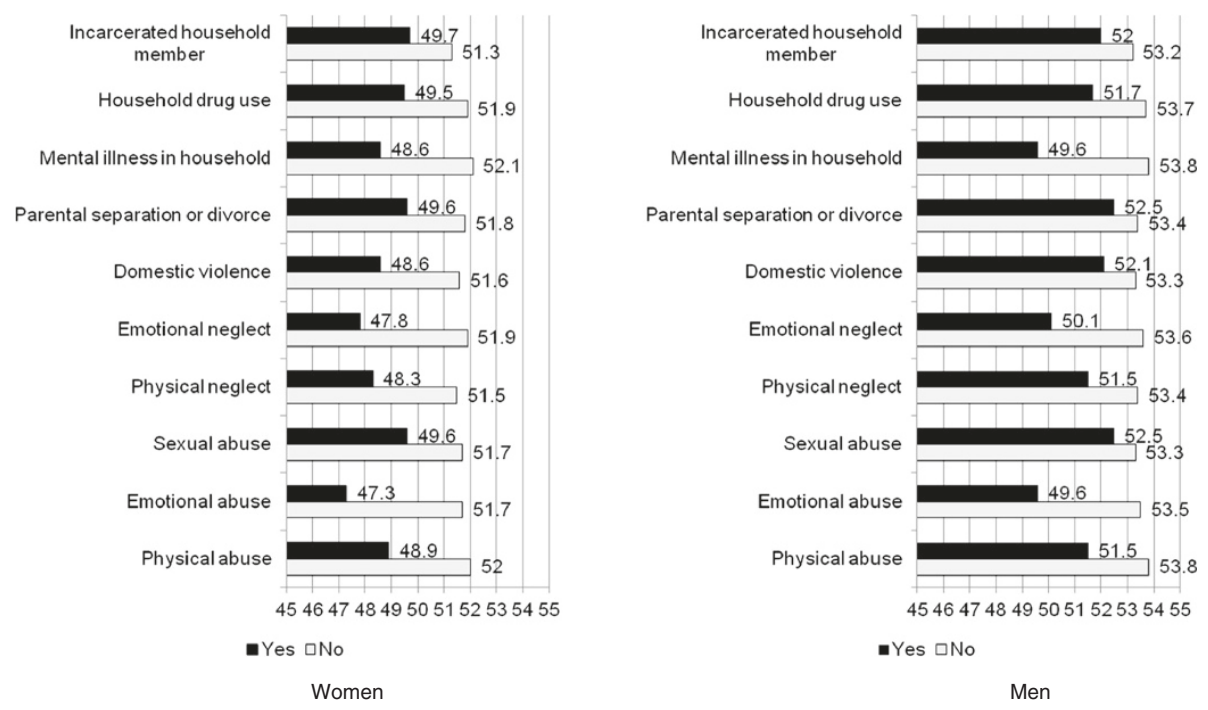

Figure 3 Mean Mental Component Summary (MCS) score by ACE status and gender.

Our findings confirm results of earlier research suggesting sex differences in smoking behavior and pattern . Although negative affect, including depression, is related to smoking among both men and women, the relationship is much stronger for women [88-90]. In fact, recent research suggests that stressful childhood life events may disproportionately influence a women's decision to use drugs [48-57]. This may be due in part to differences in coping

\begin{tabular}{l} 
Table 5 Adjusted coefficients ${ }^{\mathrm{a}}$ and $95 \%$ confidence \\
intervals for the relationships between ACEs and \\
psychological distress, by sex \\
\hline ACE \\
\begin{tabular}{lll} 
Females & Maljusted \\
coefficients $^{\mathrm{a}}$ & $\begin{array}{l}\text { adjusted } \\
\text { coefficients }^{\mathrm{a}} \\
(95 \% \mathrm{Cl})\end{array}$ & $(95 \% \mathrm{Cl})$ \\
\hline
\end{tabular}
\end{tabular}

\begin{tabular}{lll}
\hline Abuse & & \\
Emotional & $-3.9(-4.8--3.0)^{*}$ & $-3.6(-4.6--2.6)^{*}$ \\
Physical & $-2.6(-3.3--1.9)^{*}$ & $-2.1(-2.7--1.5)^{*}$ \\
Sexual & $-1.8(-2.5--1.1)^{*}$ & $-0.9(-1.6--0.1)^{*}$ \\
Neglect & & \\
Emotional & $-3.7(-4.5--2.9)^{*}$ & $-3.4(-4.2--2.5)^{*}$ \\
Physical & $-2.8(-3.8--1.7)^{*}$ & $-1.9(-2.7--1.0)^{*}$ \\
Household dysfunction & & \\
Witnessing domestic violence & $-2.4(-3.2--1.5)^{*}$ & $-0.9(-1.7--0.01)^{*}$ \\
Parental separation or divorce & $-1.6(-2.3--0.9)^{*}$ & $-0.6(-1.3-0.03)$ \\
Mental illness in the household & $-3.1(-3.8--2.5)^{*}$ & $-4.0(-4.8--3.3)^{*}$ \\
Household substance abuse & $-1.7(-2.4--1.0)^{*}$ & $-1.7(-2.3--1.1)^{*}$ \\
Incarcerated household member & $-0.9(-2.1-0.2)$ & $-0.9(-2.2-0.4)$ \\
ACE score & $-1.1(-1.3--0.9)^{*}$ & $-1.0(-1.2--0.8)^{*}$ \\
\hline
\end{tabular}

${ }^{a}$ Multivariable linear regression models included age group, race, education, parental smoking during childhood, and alcohol use in past month. ${ }^{*} p<0.05$. styles and socialization [56]; females may develop more passive styles of responding to threats and distressing events as opposed to boys who may engage in a more active coping style [91-95]. Interestingly, women are often less dependent on nicotine then men [60,96-98], they are less likely to be heavy smokers [79], and have lower concentrations of cotinine (a byproduct of nicotine). Notably, however, studies have consistently found that women have lower quit rates than men $[61,62,97]$, have lower confidence in their ability to quit $[98,99]$, and often experience worse withdrawal symptoms during smoking cessation attempts [59,97]. In fact, recent research suggests that the smoking rates for adolescent and adult women may actually be increasing [100].

\section{Table 6 Sobel statistics and percent mediated. Women}

\begin{tabular}{llll}
\hline \multicolumn{3}{c}{ Sobel test $^{\mathbf{a}}$} & ${\text { \% } \text { mediated }^{\mathbf{b}}}^{\text {ACE }}$ \\
Abuse & Test Statistic (SE) & p-value & \\
Emotional & $-3.36(0.02)$ & 0.0008 & $22.0 \%$ \\
Physical & $-3.29(0.02)$ & 0.0010 & $16.8 \%$ \\
Neglect & & & \\
Physical & $-3.01(0.02)$ & 0.0026 & $14.0 \%$ \\
Household dysfunction & & & \\
Parental sep/div & $-2.88(0.01)$ & 0.0040 & $10.2 \%$
\end{tabular}

Note. Sobel test and proportion of mediation obtained from linear and logistic regression models adjusted for covariates including age group, race, education, parental smoking during childhood, and alcohol use in past month; P-values drawn from the normal distribution under the assumption of a 2-tailed z-test. The hypothesis is that the mediated effect equals zero. Excel spreadsheet created by Nathaniel R. Herr (February, 2006), Adopted from Kenny, 2006. Available at: http://nrherr.bol.ucla.edu/Mediation/logmed.html. ${ }^{a}$ Sobel test. http://www.quantpsy.org/sobel/sobel.htm

bequation $\left(c-c^{\prime}\right) / c$. 
Our study indicates that women are more likely than men to report emotional and sexual abuse and emotional neglect while men are more likely to report physical abuse and neglect. Literature has consistently indicated that women are more likely than men to report sexual abuse [101] and men are more likely than women to report physical abuse [102]. The authors could find very little research that examined emotional abuse and neglect and physical neglect by sex; specifically research that did not contain the same data used in this study. The one study we did find indicated that women were significantly more likely than men to report emotional abuse and slightly more likely than men to report emotional neglect, although not statistically significantly so [103]. This same study indicated that men were significantly more likely than women to report physical neglect, results consistent with our findings [103].

Much research has already examined potential biases and limitations of the ACE Study data. Research conducted by Felitti et al. [64] determined that respondent and nonrespondent groups were similar with regard to sociodemographic characteristics (e.g., percentages of women, mean years of education, and marital status), selfrated health, engagement in adverse health behaviors (e.g., smoking and other substance abuse), and presence of chronic diseases such as heart attack, stroke, chronic obstructive lung disease, hypertension, and diabetes. Edwards et al. [104] conducted research examining potential response bias and found that persons who did not participate in the ACE Study experienced childhood sexual abuse at the same rate as those who agreed to participate; research made possible by a dichotomous screening question about childhood sexual abuse in the health history survey. Moreover, those who participated in the study who reported sexual abuse had similar levels of current mental and physical health problems as those who did not participate and also reported sexual abuse [104]. Testretest reliability research conducted by Dube et al. [105], found that childhood sexual, physical, and emotional abuse, as well as forms of household dysfunction (i.e., mental illness in household, substance abuse in household, parental discord or divorce, incarcerated household member, and domestic violence), showed good Cohen's Kappa agreement as defined by Fleiss [106] and Landis and Koch [107] (range $=0.46-0.86$ ). Finally, while persons in the ACE Study are older, more educated, and less likely to smoke than the general population, ACE Study sexual and physical abuse estimates are similar to those derived from adult population-based surveys [108-110].

There are several limitation that warrants further examination. First, the ACE Study data are cross-sectional and do not collect specific information on temporality. Although most current literature suggests that the majority of psychiatric disorders associated with smoking occur prior to smoking initiation [29-44], other pathways have been posited (e.g., bidirectional association, common environmental and genetic factors for both, and smoking initiation prior to psychological distress) [111,112]. Notably, in a study designed to specifically examine the stresssmoking relationship among adolescents, negative life events and negative affect were related to an increase in smoking over time, with no evidence of reverse causation [35]. Additional longitudinal studies are needed to further clarify the relationships between ACEs, psychological distress, and smoking among adults. Second, there is undoubtedly more than one pathway that would lead an adolescent to smoking initiation (e.g., peer pressure). Moreover, there could be a cohort effect because participants in this study likely began to smoke at a time when smoking was more socially acceptable than it is now, and therefore the relative contribution of ACEs and psychological distress may increase or decrease as the rates of smoking decrease over time. Third, at the inception of the study, domestic violence was recognized to primarily occur against women. It is commonly known now that domestic violence occurs to both men and women in the household. Given this, our study has underestimated the prevalence of domestic violence in the household. Fourth, longitudinal follow-up studies of adults with documented childhood abuse suggested that retrospective reports of childhood abuse often underrepresented actual events [113-115]. However, in a recent study by Tourangeau and Yan [116], the authors indicate that respondents are less likely to underreport undesirable events and behaviors when the questions are self-administered and when the data are collected in private. Bias also may be introducted if there are differences in reporting retrospective information about childhood abuse by sex. In an article by Widom and Morris [114], among persons with a history of documented sexual abuse in childhood, fewer men than women later considered the event sexual abuse. Fifth, according to recent research, the joint effect of multiple ACEs on mental disorders are non-additive and often attenuate with age. This, combined with recall failure, often overestimates the effects of summary ACE scales [117]. Given this, as was found in this study, one might not expect to see a dose-response relationship between number of ACEs and psychological distress. Further research is needed to determine an appropriate summary measure for retrospective studies. Sixth, it is not plausible that women would have more exposure to several of the ACEs (eg, household dysfunction) than men. This suggests that women are more sensitive to several of the ACE measures or are more willing to report them. Finally, psychological distress is a non-specific concept that can encompass everything from temporary negative emotion to chronic mental disorders. 
However, research suggests that the MCS is a good predictor of depressive disorders [76].

This study has important policy implications for public health approaches to smoking cessation. Despite increasingly stronger disincentives to smoking, including higher tobacco taxes and fewer places to smoke, the rate of smoking in the U.S. fell only slightly, from $20.9 \%$ in 2005 to $19.3 \%$ in 2010 . At this slow rate of decline, by 2020 the adult smoking rate will only have fallen to about 17\% [118]. Given the strong association between ACEs and smoking, interventions targeted to trauma survivors may enhance the effectiveness of broader-based antismoking efforts.

\section{Conclusions}

Several recent articles have suggested that persons who have experienced ACEs are more likely to smoke, but the exact mechanism linking ACEs with adult current smoking has not been fully elucidated. This research provides preliminary evidence that among women, psychological distress may be a potential intermediate variable in the relationship between ACEs and adult current smoking. As such, when addressing smoking cessation in clinical practice, it may be important to understand not only psychological distress, but the underlying role of childhood trauma. Having knowledge about childhood trauma history in clinical practice may provide the opportunity to integrate trauma focused interventions. Moreover, to create effective intervention and prevention programs, research should be conducted to further elucidate the causes, developmental paths, and critical points that link ACEs to smoking, especially in adolescence [57]. Identifying potential modifiable risk factors for smoking onset in adolescents (e.g., ACEs), as well as building resiliency and positive social support networks for abused children may decrease the prevalence of smoking among children and adolescents exposed to maltreatment. Research examining additional potential covariates, including temporality, intensity, frequency, and duration of maltreatment [119,120]; victim's past and current environmental circumstances; and genetic influences on smoking behavior and mental illness is also warranted [121,122].

\section{Competing interests}

The authors declare that they have no competing interests.

\section{Authors' contributions}

TWS developed the research question, conducted the statistical analysis, conducted the literature review, and wrote the initial draft of the manuscript. VJE, SRD and SD assisted with the statistical analysis. MW, AWP, SR, VJE, and $J B C$ assisted with subject matter content. All authors read and approved the final manuscript.

\section{Disclaimer}

The findings and conclusions in this article are those of the authors and do not necessarily represent the official position of the Centers for Disease Control and Prevention.

\section{Author details}

'Office of Public Health Preparedness and Response, Office of Science and Public Health Practice, Centers for Disease Control and Prevention, Atlanta GA, USA. ${ }^{2}$ National Center for Chronic Disease Prevention and Health Promotion, Division of Adult and Community Health, Centers for Disease Control and Prevention, Atlanta, GA, USA. ${ }^{3}$ National Center for Chronic Disease Prevention and Health Promotion, Office of Smoking and Health, Atlanta, GA, USA. ${ }^{4}$ Walden University, Minneapolis, MN, USA. ${ }^{5}$ Western Michigan University, Kalamazoo, MI, USA. 'Williamsville Wellness, Hanover, VA, USA. ${ }^{7}$ Office of Surveillance, Epidemiology, and Laboratory Services, Centers for Disease Control and Prevention, 2500 Century Pkwy Mailstop E97, Atlanta, GA 30345, USA.

Received: 22 February 2012 Accepted: 17 May 2012

Published: 13 July 2012

\section{References}

1. Flaherty EG, Thompson R, Litrownik AJ, Zolotor AJ, Dubowitz H, Runyan DK, English DJ, Everson MD: Adverse childhood exposures and reported child health at age 12. Academic Pediatrics 2009, 9:150-156.

2. U.S. Department of Health and Human Services: Administration for Children and Families. Administration on Children, Youth, and Families. Children's Bureau. Child maltreatment. 2010. http://www.acf.hhs.gov/programs/cb/ pubs/cm10/cm10.pdf.

3. Anda RF, Felitti VJ, Bremner JD, Walker JD, Whitfield C, Perry BD, Dube SR, Giles WH: The enduring effects of abuse and related adverse experiences in childhood. A convergence of evidence from neurobiology and epidemiology. European Archives of Psychiatry and Clinical Neuroscience 2006, 256:174-186.

4. Arias I: The legacy of child maltreatment: long-term health consequences for women. Journal of Womens Health 2004, 13:468-473.

5. Repetti RL, Taylor SE, Seeman TE: Risky families: family social environments and the mental and physical health of offspring. Psychol Bull 2002, 128:330-366.

6. Taylor SE, Lerner JS, Sage RM, Lehman BJ, Seeman TE: Early environment, emotions, responses to stress, and health. J Personal 2004, 72:1365-1393.

7. Sroufe AL, Rutter M: The domain of developmental psychopathology. Child Development 1984, 55:17-29.

8. McEwen BS, Stellar E: Stress and the individual. Mechanisms leading to disease. Arch Intern Med 1993, 153:2093-2101.

9. Leitenberg H, Gibson LE, Novy PL: Individual differences among undergraduate women in methods of coping with stressful events: the impact of cumulative childhood stressors and abuse. Child Abuse and Neglect 2004, 28:181-192.

10. Stevens SL, Colwell B, Smith DW, Robinson J, McMillan C: An exploration of self-reported negative affect by adolescents as a reason for smoking: implications for tobacco prevention and intervention programs. Preventive Medicine 2005, 41:589-596.

11. Boney-McCoy S, Finkelhor D: Psychosocial sequelae of violent victimization in a national youth sample. $J$ Consulting and Clinical Psych 1995, 5:726-736.

12. Edwards VJ, Holden GW, Anda RF, Felitti VJ: Relationship between multiple forms of childhood maltreatment and adult mental health in community respondents: results from the adverse childhood experiences study. Am J Psychiatry 2003, 160:8.

13. Kessler RC, Gillis-Light J, Magee WJ, Kendler KS, Eaves L: Childhood adversity and adult psychopathology. In Stress and Adversity Over the Life Course: Trajectories and Turning Points. Edited by Gotlib IH, Wheaton B. New York: Cambridge University Press; 1997:29-49.

14. Ridner SH: Psychological distress: concept analysis. J Adv Nurs 2004, 45:536-545.

15. Balfour DJ, Fagerstrom KO: Pharmacology of nicotine and its therapeutic use in smoking cessation and neurodegenerative disorders. Pharmacol Ther 1996, 72:51-81.

16. Glassman AH, Helzer JE, Covey LS, Cottler LB, Stetner F, Tipp JE, Johnson J: Smoking, smoking cessation, and major depression. JAMA 1990, 264:1546-1549.

17. Lerman C, Audrain J, Orleans CT, Boyd R, Gold K, Main D, Caporaso N: Investigation of mechanisms linking depressed mood to nicotine dependence. Addict Behav 1996, 21:9-19. 
18. Penny GN, Robinson JO: Psychological resources and cigarette smoking in adolescents. Br J Psychol 1986, 77(Pt 3):351-357.

19. Escobedo LG, Reddy M, Giovino GA: The relationship between depressive symptoms and cigarette smoking in US adolescents. Addiction 1998, 93(3):433-440

20. Kassel JD, Stroud LR, Paronis CA: Smoking, stress, and negative affect: correlation, causation, and context across stages of smoking. Psychol Bull 2003, 129(2):270-304.

21. Koval JJ, Pederson LL, Mills CA, McGrady GA, Carvajal SC: Models of the relationship of stress, depression, and other psychosocial factors to smoking behavior: a comparison of a cohort of students in grades 6 and 8. Preventive Medicine 2000, 30(6):463-477.

22. Mermelstein R: Ethnicity, gender and risk factors for smoking initiation: an overview. Nicotine and Tobacco Research 1999, 1(Suppl 2):S39-S43.

23. West R: Beneficial effects of nicotine: fact or fiction?. Addiction 1993, 88(5):589-590.

24. Jamner LD, Shapiro D, Jarvik ME: Nicotine reduces the frequency of anger reports in smokers and nonsmokers with high but not low hostility: an ambulatory study. Exp Clin Psychopharmacol 1999, 7(4):454-463.

25. Whalen CK, Jamner LD, Henker B, Delfino RJ: Smoking and moods in adolescents with depressive and aggressive dispositions: evidence from surveys and electronic diaries. Heal Psychol 2001, 20(2):99-111.

26. Covey LS, Glassman AH, Stetner F: Depression and depressive symptoms in smoking cessation. Comprehensive Psychiatry 1990, 31(4):350-354.

27. Covey LS, Glassman AH, Stetner F: Major depression following smoking cessation. Am J Psychiatry 1997, 154(2):263-265.

28. Covey LS, Tam D: Depressive mood, the single-parent home, and adolescent cigarette smoking. Am J Public Health 1990, 80(11):1330-1333.

29. Dierker LC, Donny E: The role of psychiatric disorders in the relationship between cigarette smoking and DSM-IV nicotine dependence among young adults. Nicotine and Tobacco Research 2008, 10:439-446.

30. Breslau N, Peterson EL, Schultz LR, Chilcoat HD, Andreski P: Major depression and stages of smoking. A longitudinal investigation. Arch Gen Psychiatry 1998, 55(2):161-166.

31. Dierker LC, Avenevoli S, Merikangas KR, Flaherty BP, Stolar M: Association between psychiatric disorders and the progression of tobacco use behaviors. Journal of the American Academy of Child and Adolescent Psychiatry 2001, 40(10):1159-1167.

32. Fergusson DM, Goodwin RD, Horwood L: Major depression and cigarette smoking: results of a 21-year longitudinal study. Psychol Med 2003, 33(8):1357-1367.

33. Kandel DB, Davies M: Adult sequelae of adolescent depressive symptoms. Arch Gen Psychiatry 1986, 43(3):255-262.

34. Patton GC, Carlin JB, Coffey C, Wolfe R, Hibbert M, Bowes G: Depression, anxiety, and smoking initiation: a prospective study over 3 years. Am J Public Health 1998, 88(10):1518-1522.

35. Wills TA, Sandy JM, Yaeger AM: Stress and smoking in adolescence: a test of directional hypotheses. Heal Psychol 2002, 21(2):122-130.

36. Breslau N: Psychiatric comorbidity of smoking and nicotine dependence. Behav Genet 1995, 25(2):95-101.

37. Feldner MT, Babson KA, Zvolensky MJ: Smoking, traumatic event exposure, and post-traumatic stress: a critical review of the empirical literature. Clin Psychol Rev 2007, 27(1):14-45.

38. de Leon J, Dadvand M, Canuso C, White AO, Stanilla JK, Simpson GM: Schizophrenia and smoking: an epidemiological survey in a state hospital. Am J Psychiatry 1995, 152(3):453-455.

39. Hughes JR, Hatsukami DK, Mitchell JE, Dahlgren LA: Prevalence of smoking among psychiatric outpatients. Am J Psychiatry 1986, 143:993-997.

40. Williams JM, Ziedonis D: Addressing tobacco among individuals with a mental illness or an addiction. Addict Behav 2004, 29(6):1067-1083.

41. Ziedonis DM, Kosten TR, Glazer WM, Frances RJ: Nicotinedependence and schizophrenia. Hospital and Community Psychiatry 1994, 45(3):204-206

42. Chilcoat HD, Breslau N: Pathways from ADHD to early drug use. Journal of the American Academy of Child and Adolescent Psychiatry 1999, 38(11):1347-1354.

43. Milberger S, Biederman J, Faraone SV, Chen L, Jones J: ADHD is associated with early initiation of cigarette smoking in children and adolescents. Journal of the American Academy of Child and Adolescent Psychiatry 1997. 36(1):37-44

44. Pomerleau OF, Downey KK, Stelson FW, Pomerleau CS: Cigarette smoking in adult patients diagnosed with attention deficit hyperactivity disorder. J Subst Abus 1995, 7(3):373-378.
45. Douglas KR, Chan G, Gelernter J, Arias AJ, Anton RF, Weiss RD, Brady K, Poling J, Farrer L, Kranzler HR: Adverse childhood events as risk factors for substance dependence: Partial mediation by mood and anxiety disorders. Addict Behav 2010, 35:7-13.

46. Lo CC, Cheng TC: The impact of childhood maltreatment on young adults' substance abuse. American Journal of Drug and Alcohol Abuse 2007, 33:139-146.

47. DeWit DJ, MacDonald K, Offord DR: Childhood stress and symptoms of drug dependence in adolescence and early adulthood: social phobia as a mediator. American Journal of Orthopsychiatry 1999, 69:61-72.

48. Simpson TL, Miller WR: Concomitance between childhood sexual and physical abuse and substance use problems. A review. Clin Psychol Rev 2002, 22:27-77.

49. White HR, Widom CS: Three potential mediators of the effects of child abuse and neglect on adulthood substance use among women. Journal of Studies on Alcohol and Drugs 2008, 69:337-347.

50. Mokdad AH, Marks JS, Stroup DF, Gerberding JL: Actual causes of death in the United States, 2000. JAMA 2004, 291:1238-1245.

51. Acierno RA, Kilpatrick DG, Resnick HS, Saunders BE, Best CL: Violent assault, posttraumatic stress disorder, and depression. Risk factors for cigarette use among adult women. Behav Modif 1996, 20:363-384.

52. Anda RF, Croft JB, Felitti VJ, Nordenberg D, Giles WH, Williamson DF, Giovino GA, et al: Adverse childhood experiences and smoking during adolescence and adulthood. JAMA 1999, 282:1652-1658.

53. Dube SR, Felitti VJ, Dong M, Giles WH, Anda RF: The impact of adverse childhood experiences on health problems: evidence from four birth cohorts dating back to 1900. Preventive Medicine 2003, 37:268-277.

54. Edwards VJ, Anda RF, Gu D, Dube SR, Felitti VJ: Adverse childhood experiences and smoking persistence in adults with smoke-related symptoms and illness. The Permanente Journal 2007, 11:5-7.

55. Nichols HB, Harlow BL: Childhood abuse and risk of smoking onset. Journal of Epidemiology and Community Health 2004, 58:402-406.

56. Simantov E, Schoen C, Klein JD: Health-compromising behaviors: why do adolescents smoke or drink? identifying underlying risk and protective factors. Archives of Pediatrics and Adolescent Medicine 2000, 154:1025-1033.

57. Widom CS, Marmorstein NR, White HR: Childhood victimization and illicit drug use in middle adulthood. Psychol Addict Behav 2006, 20:394-403.

58. Byrne DG, Mazanov J: Source of adolescent stress, smoking and the use of other drugs. Stress Medicine 1999, 15:215-227.

59. Perkins KA, Donny E, Caggiula AR: Sex differences in nicotine effects and self-administration: review of human and animal evidence. Nicotine and Tobacco Research 1999, 1:301-315.

60. Perkins KA, Jacobs L, Sanders M, Caggiula AR: Sex differences in the subjective and reinforcing effects of cigarette nicotine dose. Psychopharmacology 2002, 163:194-201.

61. Perkins KA, Scott J: Sex differences in long-term smoking cessation rates due to nicotine patch. Nicotine and Tobacco Research 2008, 10:1245-1250.

62. Wetter DW, Kenford SL, Smith SS, Fiore MC, Jorenby DE, Baker TB: Gender differences in smoking cessation. J Consult Clin Psychol 1999, 67:555-562.

63. Edwards VJ, Anda RF, Felitti VJ, Dube SR: Adverse childhood experiences and health-related quality of life as an adult. In Health Consequences of Abuse in the Family: A Clinical Guide for Evidence-Based Practice. Edited by Kendell T. KA Washington, DC: American Psychiatric Association; 2004:81-93.

64. Felitti VJ, Anda RF, Nordenberg D, Williamson DF, Spitz AM, Edwards V, Koss MP, Marks JS: Relationship of childhood abuse and household dysfunction to many of the leading causes of death in adults. The Adverse Childhood Experiences (ACE) Study. American Journal of Preventive Medicine 1998, 14:245-258.

65. Ware JE, Kosinski M, Keller SD: SF-36 Physical and Mental Health Summary Scales: A User's Manual. Boston, MA: New England Medical Center, the Health Institute; 1994.

66. Ware JE, Snow KK, Kosinski M, Gandek B: SF-36 Health Survey Manual and Interpretation Guide. Boston, MA: New England Medical Center, The Health Institute; 1993.

67. Straus M: Gelles RJ: Physical violence in American families: Risk factors and adaptation to violence in 8,145 families. New Brunswick: Transaction Press; 1990.

68. Wyatt GE: The sexual abuse of Afro-American and white-American women in childhood. Child Abuse and Neglect 1985, 9:507-519.

69. Schoenborn CA, National Center for Health Statistics: Advanced Data fromVital and Health Statistics, No. 205. Exposure to alcoholism in the family. United States; 1988. http://www.cdc.gov/nchs/data/ad/ad205.pdf.

70. Bernstein DP, Stein JA, Newcomb MD, Walker E, Pogge D, Ahluvalia T, Stokes J, Handelsman L, Medrano M, Desmond D, Zule W: Development 
and validation of a brief screening version of the Childhood Trauma Questionnaire. Child Abuse and Neglect 2003, 27:169-190

71. Dong M, Anda RF, Felitti VJ, Dube SR, Williamson DF, Thompson TJ, Loo CM, Giles WH: The interrelatedness of multiple forms of childhood abuse, neglect, and household dysfunction. Child Abuse and Neglect 2004, 28:771-784.

72. Ware JE, Sherbourne CD: The MOS 36-item short-form health survey (SF-36). I. Conceptual framework and item selection. Medical Care 1992, 30:473-483.

73. Fukuhara S, Ware JE, Kosinski M, Wada S, Gandek B: Psychometric and clinical tests of validity of the Japanese SF-36 Health Survey. Journal of Clinical Epidemiology 1998, 51:1045-1053.

74. Ware JE, Gandek B, Group IP: The SF-36 Health Survey: Development and use in mental health research and the IQOLA project. Int I Ment Heal 1994, 23:49-73.

75. Beusterien KM, Steinwald B, Ware JE: Usefulness of the SF-36 Health Survey in measuring health outcomes in the depressed elderly. Journal of Geriatric Psychiatry and Neurology 1996, 9:13-21.

76. Silveira E, Taft C, Sundh V, Waern M, Palsson S, Steen B: Performance of the SF-36 health survey in screening for depressive and anxiety disorders in an elderly female Swedish population. Quality of Life Research 2005, 14:1263-1274

77. Weinstein MC, Berwick DM, Goldman PA, Murphy JM, Barsky AJ: A comparison of three psychiatric screening tests using receiver operating characteristic (ROC) analysis. Medical Care 1989, 27:593-607.

78. Wells KB, Burnam MA, Rogers W, Hays R, Camp P: The course of depression in adult outpatients. Results from the Medical Outcomes Study. Arch Gen Psychiatry 1992, 49:788-794.

79. Giovino GA, Schooley MW, Zhu BP, Chrismon JH, Tomar SL, Peddicord JP, Merritt RK, Husten CG, Eriksen MP: Surveillance for selected tobacco-use behaviors-United States, 1990-1994. MMWR Morb Mortal Wkly Rep 1994, 43(suppl 3):1-43.

80. Nelson DE, Holtzman D, Bolen J, Stanwyck CA, Mack KA: Reliability and validity of measures from the Behavioral Risk Factor Surveillance System (BRFSS). Social and Preventive Medicine 2001, 46(Suppl 1):S03-S42.

81. Nelson DE, Powell-Griner E, Town M, Kovar MG: A comparison of national estimates from the National Health Interview Survey and the Behavioral Risk Factor Surveillance System. Am J Public Health 2003, 93:1335-1341.

82. Baron RM, Kenny DA: The moderator-mediator variable distinction in social psychological research: conceptual, strategic, and statistical considerations. J Personal Soc Psychol 1986, 51:1173-1182.

83. Kraemer HC, Stice E, Kazdin A, Offord D, Kupfer D: How do risk factors work together? Mediators, moderators, and independent, overlapping, and proxy risk factors. Am J Psychiatry 2001, 158:848-856.

84. MacKinnon DP: Introduction to statistical mediation analysis. New York, NY: Lawrence Erlbaum Assoc; 2008.

85. Sobel ME: Asymptotic intervals for indirect effects in structural equations models. In Sociological methodology. Edited by Leinhart S. San Francisco: Jossey-Bass; 1982:312.

86. MacKinnon DP, Dwyer JH: Estimating mediated effects in prevention studies. Eval Rev 1993, 17:144-158.

87. Jiang N, Ling PM: Reinforcement of smoking and drinking: tobacco marketing strategies linked with alcohol in the United States. Am J Public Health 2011, 101(10):1942-1954.

88. Brandon TH, Baker TB: The Smoking Consequences Questionnaire: The subjective expected utility of smoking in college students. Psychol Assess 1991, 3:484-491.

89. Husky MM, Mazure CM, Paliwal P, McKee SA: Gender differences in the comorbidity of smoking behavior and major depression. Drug and AlcoholDependence 2008, 93(1-2):176-179.

90. Mckee SA, Maciejewski PK, Falba T, Mazure CM: Sex differences in the effects of stressful life events on changes in smoking status. Addiction 2003, 98(6):847-855.

91. Compas BE, Malcarne VL, Fondacaro KM: Coping and stressful events in older children and adolescents. J Consult Clin Psychol 1988, 56:405-411.

92. De Boo GM, Spiering M: Pre-adolescent gender differences in association between temperament, coping, and mood. Clinical Psychology andPsychotherapy 2010, 17(4):313-320.

93. Groe MW, Thomas SP, Shoffner D: Adolescent stress and coping: a longitudinal study. Res Nurs Heal 1992, 15:209-217.

94. Nolen-Hoeksema S, Girgus JS: The emergence of gender differences in depression during adolescence. Psychol Bull 1994, 115:424-443.
95. Peterson AC, Sarigiani PA, Kennedy RE: Adolescent depression: why more girls. Journal of Youth and Adolescence 1991, 20:247-271.

96. Bjornson W, Rand C, Connett JE, Lindgren P, Nides M, Pope F, Buist AS, Hoppe-Ryan C, O'Hara P: Gender differences in smoking cessation after 3 years in the Lung Health Study. Am J Public Health 1995, 85(2):223-230.

97. Royce JM, Corbett K, Sorensen G, Ockene J: Gender, social pressure, and smoking cessations: the Community Intervention Trial for Smoking Cessation (COMMIT) at baseline. Social Science and Medicine 1997, 44(3):359-370.

98. Ward KD, Klesges RC, Zbikowski SM, Bliss RE, Garvey AJ: Gender differences in the outcome of an unaided smoking cessation attempt. Addict Behav 1997, 22(4):521-533.

99. Etter JF, Prokhorov AV, Perneger TV: Gender differences in the psychological determinants of cigarette smoking. Addiction 2002, 97:733-743.

100. De Von Figueroa-Moseley C, Landrine H, Klonoff EA: Sexual abuse and smoking among college student women. Addict Behav 2004, 29(2):245-251

101. Finkelhor D, Baron L: Risk factors for child sexual abuse. Journal of Interpersonal Violence 1986, 1:43-71.

102. Thompson MP, Kingree JB, Desai S: Gender differences in long-term health consequences of physical abuse of children: data from a nationally representative survey. Am J Public Health 2004, 94(4):599604.

103. Scher CD, Forde DR, McQuaid JR, Stein MB: Prevalence and demographic correlates of childhood maltreatment in an adult community sample. Child Abuse and Neglect 2004, 28:167-180.

104. Edwards VJ, Anda RF, Nordenberg DF, Felitti VJ, Williamson DF, Wright JA: Bias assessment for child abuse survey: factors affecting probability of response to a survey about childhood abuse. Child Abuse and Neglect 2001, 25:307-312.

105. Dube SR, Williamson DF, Thompson T, Felitti VJ, Anda RF: Assessing the reliability of retrospective reports of adverse childhood experiences among adult $\mathrm{HMO}$ members attending a primary care clinic. Child Abuse and Neglect 2004, 28:729-737.

106. Fleiss JL: The measurement of interrater agreement. In Statistical methods for rates and proportions. 2nd edition. New York: John Wiley and Sons, Inc; 1981:212-236.

107. Landis JR, Koch GG: The measurement of observer agreement for categorical data. Biometrics 1977, 33:159-174.

108. Dong M, Anda RF, Dube SR, Giles WH, Felitti VJ: The relationship of exposure to childhood sexual abuse to other forms of abuse, neglect, and household dysfunction during childhood. Child Abuse and Neglect 2003, 27:625-639.

109. Finkelhor D, Hotaling G, Lewis IA, Smith C: Sexual abuse in a national survey of adult men and women: prevalence, characteristics, and risk factors. Child Abuse and Neglect 1990, 14:19-28.

110. MacMillan HL, Fleming JE, Trocme N, Boyle MH, Wong M, Racine YA Beardslee WR, Offord DR: Journal of theAmerican Medical Association 1997, 278:131-135.

111. Costello EJ, Erkanli A, Federman E, Angold A: Development of psychiatric comorbidity with substance abuse in adolescents: effects of timing and sex. Journal of Clinical Child Psychology 1999, 28:298-311.

112. Moolchan ET, Ernst M, Henningfield JE: A review of tobacco smoking in adolescents: treatment implications. Journal of the American Academy of Child and Adolescent Psychiatry 2000, 39:682-693.

113. Hardt J, Rutter M: Validity of adult retrospective reports of adverse childhood experiences: review of the evidence. Journal of Child Psychology and Psychiatry and Allied Disciplines 2004, 45(2):260-273.

114. Widom CS, Morris S: Accuracy of adult recollections of childhood victimization, part 2: childhood sexual abuse. Psychol Assess 1997, 9:34-46.

115. Widom CS, Shepard R: Accuracy of adult recollection of childhood victimization: Part 1. Childhood physical abuse. Psychol Assess 1996, 8:412-421.

116. Tourangeau R, Yan T: Sensitive questions in surveys. Psychol Bull 2007, 133(4):859-883.

117. Green JG, McLaughlin KA, Berglund PA, Gruber MJ, Sampson NA, Zaslavsky AM, Kessler RC: Childhood adversities and adult psychiatric disorders in the National Comorbidity Survey Replication I. Arch Gen Psychiatry 2010, 67(2):113-123.

118. King B, Dube S, Kaufmann R, Shaw L, Pechacek T: Vital signs: cigarette smoking among adults aged $\geq 18$ years - United States, 2005-2010. MMWR Morb Mortal Wkly Rep 2011, 60(35):1207-1212. 
119. Cicchetti D, Toth SL: A developmental psychopathology perspective on child abuse and neglect. Journal of the American Academy of Child and Adolescent Psychiatry 1995, 34:541-565.

120. Kaplow JB, Widom CS: Age of onset of child maltreatment predicts long-term mental health outcomes. J Abnorm Psychol 2007, 116:176-187.

121. Batra V, Patkar AA, Berrettini WH, Weinstein SP, Leone FT: The genetic determinants of smoking. Chest 2003, 123:1730-1739.

122. Yoshimasu K, Kiyohara C: Genetic influences on smoking behavior and nicotine dependence: a review. Journal of Epidemiology 2003, 13:183-192.

doi:10.1186/1747-597X-7-30

Cite this article as: Strine et al:: The mediating sex-specific effect of psychological distress on the relationship between adverse childhood experiences and current smoking among adults. Substance Abuse

Treatment, Prevention, and Policy 2012 7:30.

\section{Submit your next manuscript to BioMed Central and take full advantage of:}

- Convenient online submission

- Thorough peer review

- No space constraints or color figure charges

- Immediate publication on acceptance

- Inclusion in PubMed, CAS, Scopus and Google Scholar

- Research which is freely available for redistribution 